\title{
Preparation of a Kind of Bee pollen Effervescent Tablets
}

\author{
JieweiZhang ${ }^{1, a}$, ZeyuanHuang ${ }^{1, b *}$ \\ ${ }^{1}$ College of Food Science and Engineering, Wuhan Polytechnic University, Wuhan 430023

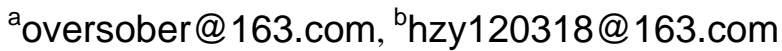 \\ *Corresponding author: Zeyuan Huang, e-mail: hzy120318@163.com
}

Keywords : bee pollen, effervescent tablets, disintegrate.

\begin{abstract}
Objective]The aim of the research is to develop a kind of bee pollen effervescent tablets. [Method] With bee pollen power and pregelatinized starch as main raw materials, the matching accessories are chosen by the orthogonal test to select the production technology of the bee pollen effervescent tablets. [Result] The optimized formula of the bee pollen effervescent tablets is bee pollen power $45 \%$, pregelatinized starch $29.3 \%$, citric acid $12.2 \%$, sodium bicarbonate $9 \%$, sodium cyclamate $2.0 \%$, Xylitol7.0\%, Xanthan gum0.5\%, PEG6000 2.0\%.[Conclusion] The bee pollen effervescent tablets prepared by this method which is simple and feasible, have stable quality and good taste, meet pharmacopeia standards, disintegrate rapidly and are easy to take.
\end{abstract}

\section{Introduction}

Since ancient times, bee pollen is considered as a kind of very good food and drug and there are a lot of records in the ancient literature.Bee pollen is composed of fructose and glucose and other sugars, easily absorded by the body. In addition to containing sugar, bee pollen also contains a variety of nutrients beneficial in normal function of cells and tissues, and organs. Bee pollenhas rich nutrition and great heat, with per kg mature heat yield about 12560 jouble. Bee pollen has no fat, is perfect health tonic and is very suitable for the elderly, children, maternity and the sickness ${ }^{[1]}$.

As a new dosage form in recent years, effervescent tablets are convenient to carry, distribute quickly in the water, with effective components easy to absorption and high bioavailability advantages. Effervescent tablets have the characteristics of both the solid preparation and the liquid preparation, have broad market prospects in pharmaceuticals and food industry. First of all, in addition to the main agents and excipients in the production of effervescent tablets, you can also addflavorings, sweeteners, coloring agents and excipients, etc, to improvethe food flavor and develp a series of different flavors of effervescence food.Secondly, the effervescent has special disintegrants-effervescent disintegrants, disintegrate rapidly in cold water, help absorption and easier to take and carry than other formulations. The effervescent tablets form the food with delicious flavor and taste, instant ready to drink, especially to cater tothe young people who love the new, extraordinary and special, has obvious advantages in the field of children and adolescents ${ }^{[2]}$. The bee pollen effervescent tablets using bee pollen as raw material made by this paper retain the nutrients and flavor of bee pollen, rapid disintegration, good taste, convenient use and convenient carrying, long shelf life, become hot and cold can of carbonated beverage after dissolving, greatly increase the drinking interest.

\section{Materials and Methods}

Materials.Bee pollen power (Wuhan LittleBee Food Co.,Ltd.), sodiumcyclamate (Guangdong huasheng food chemical company in guangzhou branch), sodium bicarbonate(Beijing the odd century chemical trading company), citric acid (Hubei and galactic chemical manufacturing company), pregelatinized starch (Tianjin peak starch development company), etc, are consumption level;absolute ethyl alcohol is of analytical grade, PEG6000 (Suzhou beautiful alum chemical industry trade company) is for medicinal level.

Instruments.TDP model sheet stampingmachine (Shanghai tensho health station pharmaceutical machinery conpany), FA2104N analytical balance (Beijing ze xiang yongxing technology 
company), GZX-9070 mbe digital display blast drying oven (GZX-9070 mbe digital display blast drying oven), 78X-Ztype tablet four eyes with meter (Shanghai yellow sea drug test instrument factory), YK-60 type granulator (Hunan ensure pharmaceutical machinery factory), WF130-30 universal mill (Changzhou music star drying equipment company).

Preparation of effervescent tablets.Technological process.

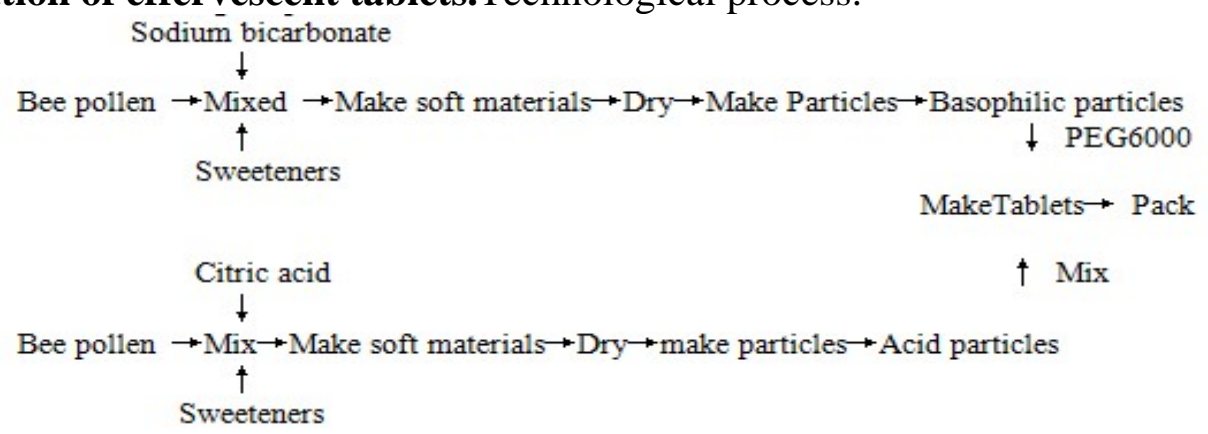

The operation points.Take bee pollen power, sodium bicarbonate,pregelatinized starch, sodium cyclamate and mix. Mixed with anhydrous ethanol spray, make the mixture can be molded into clusters, and can spread out, 20 mesh sieve, make soft material. In $50^{\circ} \mathrm{C}$ drying box for drying, so that water is below 3\%. 20 mesh to pelletize. Take bee pollen power, citric acid, pregelatinized starch, sodium cyclamate and mix. Mixed with anhydrous ethanol spray, make the mixture can be molded into clusters, and can spread out, 20 mesh sieve, make soft material. In $50^{\circ} \mathrm{C}$ drying box for drying, so that water is below 3\%. 20 mesh to pelletize. Weigh the alkali, acid, PEG6000 and mix. Tablet in the tableting machine ${ }^{[3]}$.

The formula design.The main factors affecting the effervescent tablets include sweetness, flavor, acidity of bee pollen powder content, sweetener content etc. In order to meet consumer tastes, the content of sugar and acid in theeffervescent tablets shouldbe deployed.Sensory evaluation contains the color, smell, taste, shape, according to the results, determine the optimal formula ${ }^{[4]}$.

Determination of the quality indicators. Weight determination ${ }^{[5]}$, according to inspection in accordance with the Chinese Pharmacopoeia 2010 edition an appendix I tablet weight difference. The disintegration test ${ }^{[5]}$, check according to the Chinese Pharmacopoeia 2005 version of under disintegration effervescent tablets according to law. The measurement of $\mathrm{pH}^{[5]}$,take 3 samples, plus $50^{\circ} \mathrm{C} 100 \mathrm{~mL}$ water to dissolve, after 1 minutes, measure $\mathrm{pH}$ value according to the determination method of Chinese Pharmacopoeia 2010 version of an appendix VII.The amount of $\mathrm{CO}_{2}$ in the effervescent ${ }^{[6]}$, weighthe conical flask and $100 \mathrm{~mL}$ water and 10 pieces of sample using weight precision loss method, record the total.The sample is added to the water, shaking with 20mins again precisionly weigh the conical flask until no bubbles emerge, record weight, the reducing weight is the amount of $\mathrm{CO}_{2}$.

Sensory evaluation method. Using sensory evaluation method, use respectively by color, smell, taste, posture as the target of sensory evaluation ${ }^{[7]}$.

Table IBEE POLLENEFFERVESCENTBEVERAGESCORINGREFERENCESTANDARD

\begin{tabular}{|c|c|c|c|}
\hline Color (20score) & Smell（30score） & Taste (30score) & Posture（20score） \\
\hline $\begin{array}{l}\text { Lvory without impurities } \\
\qquad(18-20)\end{array}$ & $\begin{array}{c}\text { Bee pollen unique } \\
\text { fragrance, rich }(20-30)\end{array}$ & $\begin{array}{l}\text { Has the unique taste of bee } \\
\text { pollen }(27-30)\end{array}$ & $\begin{array}{c}\text { Clear, without impirities, } \\
\text { no seperation } \\
(18-20)\end{array}$ \\
\hline $\begin{array}{l}\text { pale lvory without } \\
\text { impurities } \\
(16-18)\end{array}$ & $\begin{array}{l}\text { Have fragrance, rich } \\
\qquad(24-27)\end{array}$ & $\begin{array}{c}\text { Has the unique taste of bee } \\
\text { pollen, suitable sweet and } \\
\text { sour } \\
(24-27)\end{array}$ & $\begin{array}{l}\text { Without impirities, no } \\
\text { seperation } \\
(16-18)\end{array}$ \\
\hline $\begin{array}{c}\text { Pale yellow, slightly } \\
\text { impurity } \\
\text { (below 16) }\end{array}$ & $\begin{array}{l}\text { Have fragrance, light } \\
\text { (below 24) }\end{array}$ & $\begin{array}{c}\text { Bee pollen taste is light, not } \\
\text { palatable } \\
\text { (below 24) }\end{array}$ & $\begin{array}{l}\text { Light turbidity, impurity } \\
\text { (below 16) }\end{array}$ \\
\hline
\end{tabular}

\section{Results and Disscutions}

A. Single factor experiment done to achieve primary influcing factors of the preparation process . 
The determination of adhesive. Using absolute ethyl alcohol as adhesive, particle is not easy to agglomerate and dry quickly, products dissolve rapidly.Therefore, using absolute ethyl alcohol as adhesive, its effect is induced by the viscous and wetting tablet.

The determination of lubricant. Particles must be added lubricants before tableting with the purpose of avoiding weight variation, the sticking difficulties during the industrialized production of tablet, andmaintaining tablets's smooth appearance which is convenient to tablet smoothly ${ }^{[8]}$. Reference $^{[9]}$ shows that the lubricant PEG6000 has good lubricity, viscous resistance and watersolubility.So we choose PEG6000 as the lubricant, the single factor experiment was conducted to determine the amount of polyethylene glycol $2 \%$.

The determination of sweeteners. In order to improve the taste of bee pollen effervescent tablets, we should choose the appropriate sweetener to eliminate pungent taste sour and to reach the appropriate sweet-sour ratio ${ }^{[10]}$. In the choice of the sweetener cyclamate, sodium cyclamate is a kind of common sweeteners, the sweetness is 50 times of sucrose. Sodium cyclamate belongs to the non-nutritive sweeteners, is generally not involved in glucose metabolism, but also can not be biodegraded, is suitable for patients with diabetes and obesity.It does not produce dental caries, its sweetener tastes better than the generalsweeteners, and the single factor experiment was conducted to determine the adding amount is $2.5 \%$.

The determination of effervescent agent. Effervescent disintegrating agent is a kind of acid-base system that will produce carbon dioxide gas disintegrationwhen mixed with water.Since citric acid taste mellow, soft, refreshing, delicious, we use citric acid as acid source. All things taken intoconsideration, choose citric acid and sodium bicarbonate as effervescent disintegrating agent ${ }^{[10]}$. In practical applications, the acid dosage should be largerthan the amount of chemical reaction theoryto ensure carbonate reaction completely and weak acid of the effervescent tablets, so as to change the effervescent tablets taste sense ${ }^{[10]}$. Using single factor test, the $\mathrm{pH}$ value and taste for evaluation, results show that, when the citric acid and sodium bicarbonate mass ratio was $1.4: 1$, the $\mathrm{pH}$ value is 4.5 , the taste is best.

Orthogonal test to optimize the preparation process.According to the results of single factor test, screen factor A (effervescent disintegrating agent), B (bee pollen powder dosage), C (PEG6000 content), D(sodium cyclamate content) and carry out orthogonal test, anhydrous ethanol added according to requirements, filler pregelatinized starch to maintain weight ${ }^{[11]}$, evaluate the quality according to the sensory index score of finished products.

Table II TEST FACTORS LEVEL TABLE

\begin{tabular}{ccccc}
\hline Levels & & Factors & & C/\% $/ \%$ \\
& $\mathrm{~A} / \%$ & $\mathrm{~B} / \%$ & 1.5 & 2.0 \\
2 & 15 & 40 & 2.0 & 2.5 \\
3 & 20 & 45 & 2.5 & 3.0 \\
\hline
\end{tabular}

Table III ORTHOGONAL TEST RESULTS AND ANALYSIS

\begin{tabular}{|c|c|c|c|c|c|}
\hline Number & $\begin{array}{c}\text { A } \\
\text { Effervescent } \\
\text { disintegrating } \\
\text { agent } / \%\end{array}$ & $\begin{array}{c}\text { B Bee pollen } \\
/ \%\end{array}$ & $\underset{\text { PEG6000/\% }}{\mathrm{C}}$ & $\begin{array}{l}\text { D Sodium } \\
\text { cyclamate } \\
/ \%\end{array}$ & $\begin{array}{l}\text { Sensory } \\
\text { scores \% }\end{array}$ \\
\hline 1 & 1 & 1 & 1 & 1 & 75 \\
\hline 2 & 1 & 2 & 2 & 2 & 77 \\
\hline 3 & 1 & 3 & 3 & 3 & 74 \\
\hline 4 & 2 & 1 & 2 & 3 & 77 \\
\hline 5 & 2 & 2 & 3 & 1 & 80 \\
\hline 6 & 2 & 3 & 1 & 2 & 78 \\
\hline 7 & 3 & 1 & 3 & 2 & 70 \\
\hline 8 & 3 & 2 & 1 & 3 & 76 \\
\hline 9 & 3 & 3 & 2 & 1 & 74 \\
\hline $\mathbf{K}_{1}$ & 226 & 222 & 229 & 229 & \\
\hline $\mathrm{K}_{2}$ & 235 & 233 & 228 & 225 & \\
\hline $\mathrm{K}_{3}$ & 220 & 226 & 224 & 227 & \\
\hline $\mathbf{k}_{1}$ & 75.33 & 74.00 & 76.33 & 76.33 & \\
\hline $\mathbf{k}_{2}$ & 78.33 & 77.67 & 76.00 & 75.00 & \\
\hline $\mathrm{k}_{3}$ & 73.33 & 75.33 & 74.67 & 74.67 & \\
\hline $\mathrm{R}$ & 5.00 & 3.67 & 1.67 & 1.37 & \\
\hline
\end{tabular}


The optimal combination for flavor $\mathrm{A}_{2} \mathrm{~B}_{2} \mathrm{C}_{3} \mathrm{D}_{1}$, Factor $\mathrm{D}$ (The amount of sodium cyclamate) as the least significant factors, and has little influence on the flavor. Therefore, according to the principle of saving raw material ,we choose $\mathrm{A}_{2} \mathrm{~B}_{2} \mathrm{C}_{3} \mathrm{D}_{1}$ as the optimal formula .Through calculation, the best formula of bee pollen effervescent tablets is: bee pollen $45 \%$, pregelatinized starch 22.3\%, citric acid 12.2\%, Sodium bicarbonate 9\%, xylitol 7\%, Sodium cyclamate 2.0\%, PEG 2.0\%, Xanthan gum $0.5 \%$. The preparation process is simple and feasible, Melissa effervescent tablets prepared by the stable quality, meet the requirements of Pharmacopoeia, rapid disintegration, taste with bee pollen specific aroma.

B. Verification test.

Select three batches preferably by orthogonal test results, the tablet disintegration time were 120 , 130, 140s. The effervescent tablet has sweet and sour taste, refreshing and aromatic taste, blister fast, has smooth appearance, uniform color and bee pollen flavor. The experiment results show that this technological process is stable and feasible.

C. The quality of finished products.

Product color is yellow; morphology is round, the surface is smooth and appearance is neat; the aroma and taste has a little bee pollen aroma, sweet and sour, soft taste; moderate hardness.

\section{Summary}

Through calculation, the best formula of bee pollen effervescent tablets is:bee pollen $45 \%$, pregelatinized starch $22.3 \%$,citric acid $12.2 \%$, sodium bicarbonate $9 \%$, xylitol7\%,sodiumcyclamate 2.0\%,PEG $2.0 \%$, Xanthan gum $0.5 \%$. The preparation process is simple and feasible, Melissa effervescent tablets prepared by the stable quality, meet the requirements of Pharmacopoeia, rapid disintegration, taste with bee pollen specific aroma.

\section{References}

[1] Wu Y D, Lou Y J. A steroid fraction of chloroform extract from bee pollen of brassica campestris induces apoptosis in human prostate cancer PC - 3 cells [J]. Phytotherapy Research, 2007, 21 (11) : 1087-1091.

[2] MiJu Su, ZhiFang Mao, HaiGen Shi. Edible effervescent tablets preparation and research situation[J]. China tea processing, Vol.2 (2008), p.20 23.

[3]Sabine Inghlbrecht, Jean Paul Remon. Roller compaction and tableting of microcrystalline cellulose/drug mixtures[J]. International Journal of Pharmaceutics, Vol.161(1998), p.215 224.

[4] Jun Luan. Modern test design optimization method[M]. Shanghai: Shanghai jiaotong university press, Vol.32(1995).

[5]] SanBao Chen. Summer Sangju effervescent tablets preparation process[J]. Journal of Shanxi the doctor of traditional Chinese medicine, Vol. 5 (2011), p.612 613.

[6] National pharmacopoeia committee. The Chinese pharmacopoeia(I)[S]. Beijing: Chemical industry press, 2000. The appendix 7 8.

[7] ZhengHao Li. Sweet potato concentrated juice processing technology research[D]. Shanxi, Shanxi university of Science and Technology, 2010.

[8] Ning Wang, XueFeng Chen, RuiPing Wang. Tea beverage effervescent tablets processing technology[J]. Journal of Food and Fermentation Industry,Vol. 33 (2007), p.151 153.

[9] R.H. H. Asgarirad, S. Honary, P. Ebrahimi. Intertional Conference on Technology[C]//The Effect of Different Lubricant Mixture and Method of Preparation on Properties of Effervescent Tablets. Advanced Materials Research , Chongqing, Vol. 129 131, 2010.

[10] HongSheng Ruan, Wei Li. Indigowoad root effervesceent tablets beverage development[J]. Journal of Anhui Agricultural Science,Vol. 7(2010), p. 3712 3713.

[11] LingHong Nie, Hong Ju. Chinese yam rhizome effervescent tablets solid beverage development[J]. Journal of Anhui Agricultural Science, Vol. 27(2009), p.13232 13233. 